\title{
Learning Management Systems and their impact on academic work
}

\author{
Malcolm Brady ${ }^{1}$ \\ Naoimh O'Reilly ${ }^{2}$ \\ Dublin City University \\ Glasnevin \\ Dublin 9 \\ Ireland \\ 1Email: malcolm.brady@dcu.ie \\ Tel.: +35317005188 \\ 2Email: naoimh.oreilly@dcu.ie \\ Tel.: +35317008075
}

\begin{abstract}
Enterprise-wide, repository-based, ubiquitously available, socially-oriented technologies such as Learning Management Systems (LMS) and virtual learning environments (VLE) are altering the nature of institutional teaching and learning processes. These technology induced changes are likely in turn to have an impact on the work experience of academics. This paper qualitatively examines the impact of LMS on several important academic relationships: with students, with colleagues, with the institution itself and with home. The research found that academics mainly used LMS as repositories of materials with some additional use for managing assessment; however, they make little use of communication, administration or monitoring features. Academics use LMS in ways and for purposes that suit themselves: use of LMS has not changed teaching habits or approaches. Academics were not concerned about impact of the technology on home-life or work-life balance. Academics reported little concern about intellectual property but nevertheless took measures to protect teaching materials.
\end{abstract}

Key Words: LMS, VLE, technology, academic, work, student, institution, home. 


\section{Learning Management Systems and their impact on academic work}

Recent teaching and learning technologies, particularly the newer enterprise-wide, ubiquitously-available, repository-based, socially-oriented technologies, provide tools to enhance student learning and increase academic efficiency. Much research has been carried out on the impact of learning technologies on students and student learning (Arbaugh, 2014; Chou \& Chou, 2011; Geddes, 2009; Proserpio \& Gioia, 2007; Selwyn, 2016). Increasingly, researchers are examining learning technologies from the point of view of the academic (Baltaci-Goktalay \& Ocak, 2006; Bothma \& Cant, 2011; Buchanan et al., 2013; Kidd, 2010; Lonn \& Teasley, 2009; Morgan, 2003; Privateer, 1999; Shelton, 2017; Westberry et al., 2015; Zhu, 2015). Given that information technologies, including learning management systems (LMSs) and virtual learning environments (VLEs), have been widely adopted by third level institutions (Walker et al., 2016, 2018), and are expected to have a deep and substantive impact on the work practices and indeed lifestyle of the individual academic (Coates et al. 2005; Cramp, 2015; Menzies \& Newson, 2007; West et al., 2007), it is important that this aspect of LMSs is studied more deeply. This paper therefore sets out to explore the impact that LMSs are having on individual academics ${ }^{1}$ and their relationships: with work, with students and colleagues, with home and with the institution itself. Given its exploratory nature, the research project took a qualitative approach manifested as a series of in-depth interviews with individual academics in a business school.

\section{Learning Management Systems}

LMSs are online e-learning systems used to support face-to-face teaching (Jackson \& Fearon, 2014) and offering a range of utilities to students, tutors and others (Love \& Fry, 2007). The LMS acts as a repository of information and as a communication mechanism between

\footnotetext{
${ }^{1}$ In the paper the words 'academic' and 'lecturer' are used interchangeably; other words used with similar meaning are faculty, faculty member, instructor and professor.
} 
students and lecturers (Naveh et al., 2010). It can also act as a vehicle for assessment (for example, assignment submission, grading and archiving) and course administration including for example registration of students on courses and grouping of students into teams (Coates et al., 2005; Schmidt, 2002). LMSs are introduced at organization level rather than at individual level and with the intention of making teaching and learning processes (Brady, 2013) more efficient (Johannesen et al. 2012). Some researchers have suggested that the advent of learning management systems such as Blackboard and Moodle has the potential to fundamentally alter the university teaching and learning environment (Conole et al, 2008).

Coates et al. (2005) suggest that there exist six major drivers behind the introduction of LMSs by universities: an improvement in the efficiency of teaching and learning processes; a promise of an enriched student learning experience, often based on constructivist teaching methodologies; increasing expectation on the part of students for some form of centralised learning management system; a felt need by universities to keep up with competitor institutions; an effective response to the strain of delivering modules to an increasingly large numbers of students; and 'a hitherto undreamt-of capacity to control and regulate teaching' $(\mathrm{p} 25)$

This change being wrought in academic life by technology is in conjunction with other changes that are taking place at university level: increased levels of hierarchical managerial control, budgetary reductions, revenue generation initiatives, efficiency and cost-reduction drives, massification and globalisation of education, and the merging of industry and academia (Bond \& O’Byrne, 2013; Parker, 2002; Parker, 2014; van Damme, 2001). While technological change may in some respects reinforce the 'pincer movements of commodification and managerialism' facing academia (Prichard \& Thomas, 2014) it will also afford new opportunities (Garrison \& Kanuka, 2004). Brynjolfsson and McAfee (2012) note that computers are not good at certain tasks that humans are good at - tasks that draw on 
insight, creativity and emotion - and suggest that the way forward is to combine the use of such human skills with technology.

The introduction of an LMS has a number of implications for lecturers. First, the lecturer's role is moving from that of transmitter of knowledge to facilitator of student learning (Coaldrake \& Stedman, 1999) : from 'sage on the stage' to 'guide on the side' (King, 1993:30). This role change has implications for individual lecturers in terms of teaching style, classroom management approaches and abilities, and digital skills. Second, the materials are stored on an organizational-level repository and consequently the academic creator no longer has full control over these materials. Multiple copies of the materials exist: on the lecturer's own desktop and laptop, on the LMS server, in university LMS archives, and on multiple student laptops and other devices. As a consequence, ownership of the intellectual property of classroom materials has become less clear. Third, while LMSs are used to monitor and control student behaviour, they also afford the institution the possibility of monitoring and controlling the behaviour of lecturers themselves (Coates et al., 2005; Johannesen et al., 2012). Fourth, the ubiquitous availability of LMSs in time and in space extends the reach of teaching-related academic work beyond the university itself to any location with an internet connection.

There is a tendency on the part of academics to extend their work activity into personal time and space (Anderson, 2006). The near-constant access to communication technologies such as email blurs the boundary between work and home (Barley et al. 2011), infringes on worklife balance (Middleton \& Cukier, 2006), increases the incidence of work-life conflict for employees and significant others (Boswell \& Olson-Buchanan, 2007), and can isolate the individual from his or her immediate environment. Dery et al. (2014) point out that in the new world of smartphones and ubiquitous connectivity the entire concept of work-life balance may need to be revisited and redefined. Barley et al. (2011) found that feelings of 
intrusion, overload and stress are due not only to the material properties of technology but also to the social processes that accompany its introduction and allow or at least accept its ubiquitous use. Tarafdar et al. (2015) found that stress induced by overuse of multiple information technologies can reduce individual and organizational productivity. It is therefore eminently possible that adoption of LMSs by universities will further blur the boundary between work and non-work and generate increased levels of stress.

An outcome of the introduction of LMSs is that teaching and learning materials, created by academics and at one time proprietary to the individual, are now stored and archived in virtual learning environments housed on servers belonging to the university. This process of articulation and codification (Nonaka, 1991) converts knowledge that was tacit and held by the individual academic into knowledge that is explicit and held by the university. With the advent of teaching repositories ownership of the intellectual property created by academics is becoming more and more unclear (Head, 2014). It is arguable that control over academic materials is gradually being ceded by the individual academic to the university.

\section{Methodology}

This paper focuses on the impact of LMS on the individual academic. It considers this impact along a number of dimensions: with the LMS itself; how the LMS is used; what it is used for; when and where it is used. It also examines the impact of this usage of LMS on key academic relationships: with students, fellow academics, the institution itself and home. The research framework is depicted in figure 1 where circles represent the main actors in the framework and full arrows the relationships between the actors; dotted arrows indicate a moderating influence. The paper proposes that the introduction of LMS into higher education institutions has created a relationship between the academic and the LMS, and this in turn has moderated the relationships between the academic and the other actors in the network: students, colleagues, the institution itself and home. Note that this paper does not concern itself with 
the lighter coloured arrows in the framework: i.e. the relationships between the LMS and the student, the LMS and the institution, and between the student and the institution; exploring these relationships is left to future research projects.

Figure 1 approximately here

The research took a qualitative approach broadly following an interpretivist epistemology designed to yield a deep understanding of the phenomenon under study by focusing on the common elements of the lived experiences of a number of individuals (Creswell, 2012). Such an approach allowed the researchers look again at experiences which may be taken for granted and to uncover new insights (Laverty, 2003). The qualitative approach took the form of ten in-depth interviews carried out for practical reasons in two rounds approximately 12 months apart. Interviews were semi-structured and took the form of a 'conversation with a purpose' (Mason, 2002, p. 62). The first round comprised interviews with six full-time members of academic staff within a business school. Respondents were self-selected in that they responded to an email from the researchers sent to all academic staff within the school (approximately 70 people) seeking participants for the research project. Interviews lasted approximately 40 minutes and were all held in early October 2015. Interviews were held in a neutral venue within the school. All interviewees had been provided with a plain language statement about the nature of the research project before the interview commenced. Both researchers were present for all but one of the interviews. One researcher led the interview and asked the questions from a pre-set table of questions (table 1); the second researcher listened, took hand-written notes, and asked occasional clarifying questions when necessary or appropriate. A second round of interviews with full-time academics in the same business school was carried out in November 2016. As the initial interviewees were mostly older and 
more established members of staff, newer members were targeted for the second round of interviews. Four members of staff responded positively to the request and these four were interviewed following the same format and using the same set of questions as for the first round of interviews. In total, ten members of academic staff were interviewed over the two rounds.

Table 1 approximately here

Each interview was recorded on two separate recording devices and then transcribed by the researchers using voice recognition software. Transcriptions were independently coded (Bryman \& Bell, 2011:584; Strauss \& Corbin, 1990) by both researchers initially using categories determined from the literature review (table 2). However, two additional categories emerged from the analysis: 'usability' of the LMS i.e. how easy or difficult the LMS was to use; and 'protective action' i.e. an action taken by the individual to protect their own materials. The researchers found a striking amount of commonality in the responses given by interviewees and theoretical saturation (Strauss \& Corbin, 1990:188) was quickly reached and further interviewing was deemed unlikely to elicit increased knowledge.

Table 2 approximately here

\section{Findings}

An open source LMS was introduced into the university in 2004 and approximately a decade later its use was made mandatory in the sense that for every course delivered within the university an LMS page was automatically opened and made available to the instructor and to 
the students. However, it was left to each individual academic themselves to determine to what extent they used or populated the LMS. The research project took place in 2015 and 2016, i.e. in the early years of mandatory use of the LMS. Detailed findings are recorded under five headings: the academic and the LMS itself, and the relationships between academic and the student, colleagues, the institution and home.

\section{Relationship with the LMS}

Respondents were found to use the LMS for three main purposes: as a repository of materials, as an aid in managing assessments, and as a communication vehicle. The primary usage of the LMS was as a repository with all respondents using it for this purpose. Several academics used the LMS for assessment and communication purposes. Little mention was made of using LMS as an aid in course administration.

All ten interviewees strongly emphasised that their main usage of the LMS was as a repository -somewhere to put lecture notes and other course materials, providing a focal point for sharing materials with students, and acting as a back-up or historical record: 'I use [the LMS] primarily for giving notes to students' [r1]2; 'I put my, my whatever materials up there ... it is a platform for sharing resources' [r2]; 'mostly use it to upload my lecture notes...I normally use [the LMS] as a repository and nothing more' [r7].

The repository based nature of the LMS resulted in it becoming the central focus or single point of contact for a course, providing a single, permanent, place for students to go for information: 'it is a key contact point for everything that you would need for the course' [r5]. The LMS repository also acted as a backup or historical record of materials: 'So, basically if I

\footnotetext{
${ }^{2}$ The ten respondents are referred to as $r 1, r 2$ and so on to $r 10$.
} 
got hit by a bus tomorrow that someone could come along and everything is there' [r5]; 'one of its biggest uses is a central repository...it's good to have all in one place' [r10].

The LMS was also used to support assessment, with seven of the ten respondents using it for this purpose. The main rationale for this was to increase efficiency, for example to make administration of assignments easier, and to provide a historical record of what was received and when. However, two respondents used the LMS to provide feedback to students: 'one of the reasons that I use [the LMS] ...is that... when students are performing poorly...they get a comment to explain why' [r3]; 'I have my rubrics set up...I would then assess the presentation...I would release these the following Thursday. Students are getting feedback within four days' [r10].

Only three of the ten respondents made use of the communication features of the LMS, and did so mainly to broadcast informational messages from lecturer to student. Attempts were made by some respondents to create discussion fora but these were largely unsuccessful as students did not participate: 'No one ever, ever, posts' [r5]; 'I haven't found anything coming back' [r6]; 'it tends to be one way between lecturer and student' [r10]. The medium of communication preferred by lecturers and students alike is email: 'I tend to get a lot of email queries outside of [the LMS] ...they [students] tend to use office hours and email instead' [r10].

All interviewees bar one regarded themselves as passive users of the technology, sticking at a basic level of usage and avoiding advanced or sophisticated functionalities: 'I probably use it for the most part in a fairly basic level' [r2]; 'I wouldn't say I'm a highly sophisticated [LMS] user ... I suppose quite minimal really’ [r5]. However, it was also clear from interviews that they were not entirely passive in their use of LMS. They were comfortable using a wide range of its features: uploading a range of materials including files and video 
clips, setting up hyperlinks to internet-based materials, adding plug-ins, setting up links to electronically receive student assignments, and offering feedback on those assignments.

A common feature of the responses is that interviewees use the LMS in ways that are useful to themselves: 'the things that I am actually using are the most valuable to me' [r6]. For example, while making materials available in a repository may be useful to students, having to place materials in only a single location is also useful to academics. Submitting assignments electronically may be handy for students; having an automatic record of receipt is useful to academics: 'it makes it easy...to have a record [that] they were submitted' [r4]. A central repository also cuts down on administration e.g. distribution and printing, and reduces queries: 'It makes it easier to put stuff on' and 'I don't print anymore' [r4]; 'if you structure it well it will reduce the amount of student queries' [r10]. Certain features were useful to academics for personal reasons: 'use of student surveys can be used as material for example for promotion... for assessing your teaching capabilities' [r10].

There was little evidence that people altered their teaching and learning style due to their use of or engagement with the LMS. If anything, the opposite held: academics picked and chose features of the LMS that fitted their particular teaching style. The interviewees did not use the LMS in a standard fashion: they selected certain features and used them in different ways according to their needs and priorities: 'I don't think it has changed my work pattern...I suppose it has more facilitated me than change anything' [r5]. However, one respondent pointed out that the LMS provided student learning benefit: 'list of references encourages students' [r10]. This same respondent also used the LMS to monitor student progress: 'can use it to track student progress... and what students are accessing' [r10].

Several respondents mentioned that the LMS was not smooth to use: 'easy to use but hard to navigate; way too clunky, way too over-spec[ifi]ed' [r7]; 'many features ... are not that clear; 
the buttons are there ... but small' [r8]; 'it turns out it is only two clicks, yeah, okay, but it's not obvious on the page where those two clicks are' [r4]; 'I generally don't use messaging function within [the LMS] because it's not on a par with email' [r10].

\section{Relationship with students}

The data provided no evidence of a shift in the relationship between lecturer and student since the advent of the LMS. Although all respondents used the LMS they did not alter their teaching style to accommodate the LMS. Respondents reported that the LMS had altered very little the nature of their interaction with students. However, respondents did feel pressure from students to use the LMS and this motivated at least one of the respondents to commence using the technology: 'to some extent we are forced into it by students...very politely they might say "Is there any chance you could put some of the stuff up on [the LMS]?"' [r6]. Other respondents pointed out that student expectations had changed. Students now expected that course materials would be available on a central repository: 'there is an expectation on the part of students as to what should be there' [r1]; 'I've heard students complain about colleagues who don't use [the LMS]' [r2]. However, one respondent felt that the LMS had increased the distance between lecturer and student and in that regard had diminished the relationship with students 'in real terms', that the university had become less 'studentcentred' [r1].

While the LMS was not perceived to have altered the relationship between lecturer and student in a substantial way, email was mentioned by several respondents as a technology that had done so: 'other things ... may have affected interactions with students but I don't think [the LMS] is one of them...What has? Email.'[r2]; 'I don't know if [the LMS] has [changed student interaction with staff]. I think, I think just technology has' [r4]; 'technology means that we are much more accessible to students' [r3]. Several respondents said that email was widely used by students to communicate with lecturers: 'they don't knock on the door 
but they are very, very happy to email me' [r3] and vice versa: 'emails would be the main way in which I would contact students' [r1].

Several respondents commented negatively on email, pointing out that reading and replying to large amounts of email from students took time away from other more useful or important academic activities: 'I think there is an expectation on the part of students that we are all connected 24 hours a day, and they want answers' [r2]; 'students email you all of the time and you could ignore them but actually with the big classes... it is essential to go in [to email] after hours' [r3]. One respondent flatly refused to accept emails from students unless the purpose of the email is to request an appointment or to point out errors in notes: 'I have a policy of not answering emails.' [r7].

\section{Relationship with colleagues}

The research project found that the LMS had relatively little impact on relationships among academics. Apart from some sharing of materials, the interviewees stated that the LMS had not affected relationships between academics either positively or negatively.

Many of the respondents viewed their LMS materials as private, between themselves and their students, and not available to others: '[the LMS] is a very private thing... we generally don't have access to other people's [LMS] pages' [r1]; 'it's not really discussed you don't share...we don't actually talk, we don't have necessarily a collective...understanding or a culture around how much we should use [the LMS]' [r3].

Academics however were prepared to share their materials with colleagues if asked: 'if somebody takes over a course from me I make my [LMS] page information accessible to them' [r1]; 'when I was going on ...leave myself I handed over all my slides' [r3]. This is particularly the case for new colleagues: 'it's just an easy way of helping a colleague who is new out, you know, just give them what you have' [r1]; 'with agreement of lecturer I was 
able to use previous material and edit it. I think it's important to ask that question first...I think most people are open to it [allowing their materials to be used by colleagues]' [r10].

However, respondents were not happy if materials were taken from the repository without their permission: 'my issue is probably with the permission basis of it. That if someone asks, no problem, but if someone is on it and taking stuff, and not really asking me, then I... [trailed off]' [r5]. Respondents did not like it when their materials were simply taken and used by others, even colleagues: 'A funny experience there recently where eh someone sent me their slides... and they were my slides' [r3]; 'if somebody wanted something, I would let them have it. Now if I found somebody using it, I might think differently' [r4]; 'I have actually seen ...people use my material on their lectures two or three years after I have taught a course - verbatim slides - so I don't like that element of it. I have no problem sharing but I, I like informed sharing' [r5];

Respondents also pointed out that they have access to the materials of other lecturers and sometimes they have availed of that access. This may have been for administrative reasons e.g. the collection of data for accreditations or the like. Respondents pointed out that it can at times be useful to be able to access the materials of a fellow academic should that person be away from the university: 'I would have oversight as result of being programme chair... [the LMS] was very useful ...for our accreditation visits because we were able to just pull stuff, or I was, as Chair. I had access...If they wanted a module outline...I could get onto [the LMS] and pull the module outline' [r5].

\section{Relationship with the institution}

The responses under this heading were related to intellectual property, monitoring and control, standardization, massification of education, and potential redundancy of faculty. 
When initially asked, most respondents expressed little outward concern about intellectual property: 'it's not something I'm worried about...if somebody wanted something I would let them have it'; 'if they want to rob my bullet points they can' [r2]. 'I have a laugh at lecturers who put copyright up. What is original material anyway? ...There is no value in notes' [r7]. However, one person mentioned that intellectual property now resides with the institution: 'I think current view is that the university owns what we produce' [r8] but that this is a greater issue than LMS: 'it's orthogonal to [i.e. independent of] [the LMS]'. Although not concerned at the present time, some respondents reported that they had concerns about intellectual property for the future: 'I am conscious, very conscious of, of IP ...because that is what we are going to be dealing with down the road' [r2].

A feature of the LMS - the automatic rolling over at institutional level of materials from one academic year to the next - did cause concern as materials are automatically made available to others: 'Now it migrates automatically and ... it probably causes a few issues' [r5]; 'to populate it with previous year material is not good' [r8]. A tension between protection of intellectual property and dissemination of knowledge was evident: 'the conundrum I think we are caught in in education really is that you, we, are not in the business of proprietary knowledge... so we have a commitment to make knowledge as widely available as we possibly can' while at the same time 'if you were to suddenly discover that somebody in another institution is using your slides..[it might come] as a bit of a shock' [r6] and 'I know of people's slides who have appeared elsewhere' [r2].

Despite the outward lack of concern over their intellectual property, six of the ten respondents had taken some precautions with respect to availability of their materials. Two main kinds of protective action were described: holding back of materials and restricting access. Holding back was sometimes done for student learning reasons e.g. not placing materials online until after the lecture so as not to pre-empt discussion in class: 'students have 
to come to class to get my editing notes - that increases attendance' [r7]. However, lecturers also held back materials in order to protect the materials from unwanted use: 'I don't give too much detail...the content of my slides is pretty scarce' [r2]; others 'cut material out...put a skeleton version of your slides up' [r3].

Respondents also restricted access to their materials: 'I have deleted people that aren't teaching the module off the list of named teachers...particularly if they were adjuncts, I mean I'm sort of feeding their consultancy businesses' [r5]. Other lecturers put up their materials as read-only files to reduce the possibility of unwanted reuse: 'I know people who make secure pdfs instead of PowerPoint slides' [r2]; 'I used to put them [course slides] up on pdf' [r3]. Another respondent puts 'name and year on the bottom of slides' to signal ownership of materials [r2].

Respondents were in general not concerned about the LMS diluting the role of the lecturer or, at the limit, making the lecturer redundant. Several respondents emphasised that the slides were a foil around which class discussion is based and that extra value was added by the lecturer in the classroom: 'The value is in notes plus lecturer' [r7]; 'it's the way you tell it, it's not just simply... what's on the slide' [r6]; 'a lot of my slides were discussion slides rather than these are the ten ways to do something... [in reference to a slide containing a picture of a parrot] the student who picks that upon [the LMS] on its own is just going to see the parrot and is not going to have a clue what is going on. So you need to have also been in the class to understand the, the discussion' [r5].

There was little support for standardization of materials within the LMS: 'at the moment we are not being prescribed how to use it ... I wouldn't like it ...to be enforced that you have to do this...' [r5]; '[regarding the] recent push for lecturers to put basic information [e.g. room number, office hours] on [the LMS] page. Whether or not that will be taken up I don't know. 
I don't feel I need to spoon-feed students' [r10]. Indeed, several respondents were against standardization indicating that modules were different in nature and that over-standardization may be detrimental to teaching and learning. One respondent however called for guidelines for the use of the LMS: 'It would be good to have a best practice guide... and more sharing of best practice' [r9].

A related point is that the LMS was seen to provide a support to universities in the ongoing massification of education: 'there is a certain amount of industrialisation of education that, that happens and that's the trade-off... But you are moving from a service that was only available to a small percentage of the total population to one that we are now trying to make available to, to everybody that is able to benefit from it' [r6]. It was intimated that the LMS may be used to reduce the effort being put into teaching: 'we are using it as a justification for pushing more responsibility onto students and taking less responsibility ourselves for student learning' [r1]. It was also suggested that the LMS may lead to the movement of teaching effort from more research active to less research active staff: 'if research is the thing that is valued most then by that reasoning teaching is not. So, if you combine that, perhaps then there is the suggestion that it doesn't matter who's doing the teaching... especially if it moves online it doesn't matter' [r3]. On the other hand, it was also pointed out that promoting an LMS and encouraging lecturers to use it highlights 'that the quality of the teaching that you do is important...[and] moderates the impact of the research agenda on the role of teaching in the university' [r3]. Some concern was expressed about the potential redundancy of academics if materials continue to be made available online. However, none of the respondents saw this as a threat to academic employment as materials will still need to be interpreted by academics. 


\section{Relationship with home}

Most of the respondents reported that they used the LMS outside of the university. One respondent worked 'wherever the laptop is' [r2]. Most said that they use the LMS at home: 'I would often do it [update material on the LMS] at home' [r3]; 'if I am on a research day and I am at home I will use it' [r1]; 'I regularly use [the LMS] on laptop at home' [r10]. However, one respondent did not use the LMS outside of the university: 'I prefer separating my other work from [university] work' [r7].

Several of the respondents said that they used the LMS outside of normal office hours: 'it is frequently outside of office hours... I would try to use it [the LMS] in that way but that [responding to student questions] would frequently be after office hours, in the evenings' [r3]; 'at nights, weekends, especially at start of semester. [I] use it quite a lot outside of office hours' [r10].

However, although use of the LMS took place at home and outside office hours, none of the respondents suggested or implied that this infringed on home life. If anything, it was suggested that the ubiquitous availability of the LMS was an advantage to academics: it allowed them work at home without having to bring home hard copy materials. Several respondents reported that they would have worked from home anyway and that using an LMS made work easier for them: 'No, no, I don't mind no. No, I find it good actually because there used to be a system that we couldn't do [use] off-campus and it used to annoy the hell out of me' $[\mathrm{r} 4]$.

\section{Discussion}

Responses from interviewees were remarkably consistent. This consistency was somewhat surprising given that respondents ranged across organizational hierarchical levels from assistant lecturer to full professor. Most of the interviewees viewed themselves as relatively 
passive users of the LMS and made use of it primarily as a repository. Of the major properties of LMSs, two were availed of to a substantial extent by the academics interviewed: the repository base, and the ubiquitous availability of the LMS in terms of time and space. The social orientation of LMSs was less utilized with communication largely restricted to one way broadcast of information from academic to student. Interviewees did not alter their teaching style to suit the technology, instead picking and choosing the elements of the technology that they found most useful to themselves. Most of the interviewees used the LMS outside of working hours and outside of the office but did not see this as an intrusion on their personal life; if anything, interviewees viewed ubiquitous availability of LMSs as a convenience. Interviewees were not concerned about the impact of the LMS on their intellectual property; nevertheless, they took precautions to protect their materials.

\section{Relationship with the LMS}

All of the respondents had engaged with the institution's LMS, many of them to a considerable extent, despite labelling themselves largely as passive users. All respondents believed that the LMS was here to stay, that there would be no going back on this particular technology by academics as individuals or by the institution as a whole. The primary use of the LMS was as a repository for course materials and the LMS had become the centre point for their courses - the place students went to, or were directed to, for information. This use of the LMS primarily as a repository and secondarily to support assessment and broadcast communication is in line with the findings of other researchers (Mahdizadeh et al, 2008; Nagy, 2016; Schoonenboom, 2014).

The research clearly found that LMSs are here to stay. Even academics who viewed themselves as laggards with respect to technology had engaged positively with the institutional LMS. It was not seen as a temporary fad but as a core technology (Shelton, 2017) leading to a permanent shift in the means of transmission of materials between lecturer 
and student. Institutional and perceived usefulness barriers identified by Buchanan et al. (2013) have been overcome, assisted by the innovation oriented culture of the organization (Zhu, 2015). In this respect the LMS has been effectively introduced by the institution, a notable achievement given that technology introductions are not always successful (Cramp, 2015; Kidd, 2010). Embedment of the LMS is in line with Walker et al. (2016) who found that institutions tend to stick with their enterprise-wide learning systems. In terms of the theoretical framework (figure 1) a solid relationship has developed between the individual academic and the LMS.

However, respondents tended to pick and choose the elements of the LMS with which they engaged and were slow to alter their teaching style to suit the LMS. Such practical and personalised usage of LMS is consistent with the findings of other researchers (Blin \& Munro, 2008; Nagy, 2016). It is clear that academics make use of LMS in ways that are practical and convenient for themselves, for example: cutting down on photocopying, providing a historical record of communications with students, and reducing the administrative burden in setting up, receiving and grading assessments. Less emphasis was placed on the use of LMS as a vehicle to increase student engagement or to monitor student performance. While individuals adopted the LMS technology, they did so only to a limited extent (Bothma \& Cant, 2011) and largely for replication purposes (Privateer, 1999), leveraging the elements of the technology that they found useful (Westberry et al., 2015) and reducing usage of less useful features (West et al., 2007). Introduction of the LMS has not led change in pedagogical practice (Walker et al., 2018). However, it is still relatively early days in the mandatory use of this LMS and so, given Kanuka and Rourke's (2008:1) finding that technology is not 'pedagogically neutral' and that working within its structure has unavoidable positive and negative consequences, it could be interesting to further investigate academic use of the LMS at a future point in time. 


\section{Relationship with students}

Although several interviewees used the LMS in response to student expectations or to stimulate student engagement with materials, improving efficiency appeared to be the dominant motive for its use. Most interviewees suggested that use of the LMS, although mandatory in the organization, had not altered the nature of the instructor-student relationship. These findings reinforce those of Blin and Munro (2008) who reported that the initial - voluntary - introduction had not altered teaching practice in a fundamental way. In terms of the theoretical framework (figure 1) the LMS has had little impact to date on the relationship between academic and student.

On the other hand, the findings show that email has had an impact, particularly on academics. Lecturers were at times inundated and overwhelmed by email. In addition, students tend to anticipate a prompt reply (Conole et al., 2008). The social norm of responsiveness to email (Barley et al., 2011) situates academics in a conflict between meeting student learning needs and carrying out other academic work. It would seem that email, not the LMS, is fulfilling the communication function between student and lecturer, largely driven by student preference. An interesting avenue for future research is to further explore this co-evolution of email and LMS.

\section{Relationship with colleagues}

While this research project found that the LMS had relatively little impact on the relationships between academics there is however some cause for concern. Lecturers were happy to share materials if asked but did not like it when others simply took materials. The automatic institutional level rollover of LMS pages from one academic year to the next has made it easier for one academic to access materials created by another academic. This appears to have caused tension as, although the institution has provided access, the individual academic is unhappy unless he or she has personally given permission to a colleague to 
access their materials. It will be interesting to see what the long run impact of this will be on relationships between academics, and between individual academics and the institution. Will academics engage in more and more protective actions such as were found in this project? Or, will academics relinquish control over their teaching materials completely and make them freely available to colleagues via the LMS? Or will the institution of the future mandate that academics place all their materials on the LMS? These questions prompt areas for further research.

\section{Relationship with the institution}

It is clear that respondents largely viewed the LMS in a positive light and as a positive development for students and for the institution. Academics used the technology in ways that were useful to themselves. They tend to use features of LMS that suit their own needs, not necessarily the needs of the institution. Academics also tend to resist, or at least be unhappy with, attempts to standardize teaching materials at institutional level. These usages support an institutional drive for increased efficiency but not an institutional drive towards increased control over teaching activity. This may pose a difficulty for institutions that desire to use LMS as a vehicle for organizing, standardizing and controlling teaching, one of the drivers for the introduction of LMS identified by Coates et al. (2005).

While lecturers regularly work outside of normal working hours and away from the university (Anderson, 2006), new communication and repository technologies extend the range of work activity that may be done outside of normal hours. The responses suggest a strong institutional work ethic with academics regularly working from home, in the evening and at weekends; long working hours appear to be an accepted part of the organizational culture. However, the extension of academic work into locations outside the office or classroom and times outside of normal working hours, afforded by the LMS, did not seem to unduly concern lecturers. If anything, academics found the ubiquitous availability of LMS a 
convenience, one that amplified their teaching activity (Kanuka \& Rourke, 2008). This suggests that successful acceptance of an LMS, and in particular its ubiquitous nature, may depend on its fit with the underlying organizational culture (Zhu, 2015).

There were however, some undercurrents of discontent. These revolved around the areas of intellectual property, standardization, monitoring and controlling, and potential redundancy. While ostensibly respondents declared that they had little concern around intellectual property, in practice people were taking precautions to protect their materials. These precautions included holding back material, removing material, simplifying material, restricting access to material, and signalling ownership. There also appears to be a tension between the role of the academic as disseminator of knowledge and the role that same knowledge plays within the core competence of the academic. Academics are caught between on the one hand holding on to their knowledge in order to secure their jobs and on the other hand releasing increasingly more of their knowledge onto institutionally owned repositories. Respondents were motivated to take precautions with respect to their intellectual property. The reasons include teaching style, pedagogical motivations and self-protection. For discussion based classes less material on the slides may make for a less-bounded and more open discussion. Less material on slides may encourage students to attend class in order to gain fuller knowledge about the point being made. Less material on the slide may also protect the property rights of academics as much of their knowledge remains in their head and is only transmitted to students during the class meeting. In terms of the theoretical framework (figure 1) the LMS does appear to have impacted on the relationship between academic and institution. This area of ownership of academic teaching materials and intellectual property is under-researched and may provide interesting and important avenues for further research; a specific topic is to delve further into the reasons for and nuances of holding back and other such precautions. 
The LMS also affords the organization the opportunity to monitor academic teaching activity in a much more precise way than ever before. LMSs can be used in tandem with institutional requirements, often dictated by outside bodies such as accreditation organizations to implement standard approaches to teaching. For example, learning outcomes, reading lists, assessment schedules and grade details can all be monitored by the organization as these materials are now available on the LMS. There was some evidence from the interviews that this was the case, although the practice was defended on pragmatic grounds and the materials were gathered for administrative rather than academic reasons. However, with much material that was traditionally held by academics now stored in central repositories, it is certainly possible that increased monitoring of academics' materials and activity could be carried out by institutions in the future; the impact of this could provide an avenue for future research.

\section{Relationship with home}

Contrary to the researchers' expectations, the research showed that the LMS had little incremental effect on life outside work. Most of the academics interviewed seemed to accept that it was perfectly normal for academic work to take place at home and that the LMS altered this arrangement very little. If anything it made it more convenient as certain work could now be completed at home more easily than before. Academics used the LMS outside of the university neither because they had to nor because they could, but because it was convenient for them. With regard to the theoretical framework (figure 1) the LMS impacted slightly on the relationship between academic and home in that it further facilitated working from home. It was not found to challenge boundaries between home and academic work as Shelton (2017) found was the case with social media.

Given the acceptance of working at home on the part of academics, it will be interesting to see how the interface between home and academic work develops in the future. Will the academic community at some point in the future roll back on this willingness to use their 
homes as work spaces? Or will academics further embrace it and make the home the primary location for their work? The implications for academics and institutions alike are major. For example, institutions may reconsider the tradition of providing individual offices for academics, especially if academics work more and more from home and costly office space remains unused for much of the time. Institutions may need to consider how to foster collegiality among an academic community that sees each other physically less and less often.

\section{Implications}

There are a number of implications of the research. First, from the point of view of the institution the introduction of the LMS has been very successful. All the academics interviewed were consistent, although perhaps limited, users of the technology. The switch by almost all academics in the institution to the learning management system took place over a relatively short timeframe. A good fit with the underlying organizational culture of innovation and extended working hours was instrumental in successful implementation of LMS. However, as academics largely used the LMS as a repository and continued with their former approach to teaching, the learning management system has not altered the way people teach. The lesson for institutions is that they must be clear on why they wish to introduce an LMS and what they want to get out of it. If they wish to change teaching practices in a fundamental way, then the mere introduction of an LMS will not suffice. If they wish to improve efficiency and standardise the look and feel of courses, teaching materials, and assessment processes then LMS will assist.

Second, from the point of view of the individual academic the introduction of LMS has also largely been successful. LMS provides a means of improving efficiency of teaching. LMS assists academics in organizing their courses by providing structure and a repository of materials that is available to students. An implication for academics is that a repository 
allows students and the institution make materials available to others, reducing the control of the individual academic over his or her materials. Although academics interviewed for this research were not overly concerned about it, control over material stored in an institutional repository may become an issue in the future. Ownership, standardisation and re-use of teaching materials stored in an institutional repository may provide interesting areas for future research.

\section{Limitations}

This research project has several limitations. First, it examined the use of LMS technology in one school in one university and therefore care must be taken in generalising from the results. Second, the research project focused on one technology - learning management systems. However, LMS is just one of many technologies - for example email and social media - that are affecting teaching and learning work in universities and the combination of these various technologies may have impact far beyond that of a single technology. Third, the research project focused on relationships of the individual academic with four entities: students, academic colleagues, the institution, and home; there may be other existing or new entities with which the academic may have relationships that may come into existence due to, or are impacted by, learning technologies, for example with known and unknown academics outside the institution, with internal professional and administrative support staff, and with university management. Finally, the research took a qualitative approach. This work could be complemented by future research that takes a quantitative approach.

\section{Conclusion}

This paper examined the extent to which learning management systems are being used by academics and the impact of this on the nature of academic work and relationships with students, colleagues, home and the institution. The research found that academics used the LMS technology on a regular basis and viewed the technology as here to stay. In that respect 
the LMS has become institutionalised and this institutionalisation occurred over a relatively short number of years. However, the LMS was not found to have had a profound effect on the nature of academic work. Individual academics chose to use the technology in ways that suit themselves. While academics used LMS outside of office hours and in locations outside the university this was largely because it suited their own lifestyle and working arrangements. Nor did lecturers change their teaching style to accommodate LMS: rather, they chose to use the elements of the LMS that best supported their pre-existing teaching style. The LMS was used as a vehicle more to improve efficiency than to improve student engagement.

The primary use of the LMS was as a repository for materials with some secondary use as an administrative support for assessment. Relatively little use was made by academics of the communication, assessment, or monitoring capabilities of LMS. Students prefer email over LMS for communication with faculty. Usage of the LMS was not found to have materially altered the relationship between lecturer and student. An interesting finding of the study is that, while ostensibly academics professed no concerns about intellectual property and accepted that teaching materials placed on an LMS de facto became more broadly available, in practice they viewed teaching materials as personal and were taking protective action including holding back, restricting access and removal of material.

\section{Note on contributors}

Malcolm Brady is an associate professor in the Business School at Dublin City University. He teaches business strategy and his research interests include strategy, business processes, game theory, and the education and health sectors.

Naoimh O'Reilly is an assistant professor in the Business School at Dublin City University, and a PhD candidate at Lancaster University. She teaches marketing and she researches in the area of the student educational experience and technology enhanced learning. 


\section{ORCID}

Malcolm Brady https://orcid.org/0000-0002-4276-3976

Naoimh O’Reilly https://orcid.org/0000-0003-1730-1603

\section{References}

Anderson, G. (2006). Carving out time and space in the managerial university. Journal of Organizational Change Management 19(5), 578-592.

Arbaugh, J. B. (2014). What might online delivery teach us about blended management education? Prior perspectives and future directions. Journal of Management Education, 38(6), 784-817.

Baltaci-Goktalay, S. \& Ocak, M.A. (2006). Faculty adoption of online technology in higher education. Turkish Online Journal of Educational Technology, 5(4), 37-43.

Barley, S.R., Myerson D.E. \& Grodal, S. (2011). Email as a source and symbol of stress. Organization Science 22(4), 887-906.

Blin, F. \& Munro, M. (2008). Why hasn't technology disrupted academics' teaching practices? Understanding resistance to change through the lens of activity theory. Computers \& Education 50(2), 475-490.

Bond, C. \& O'Byrne, D. (2013). If it moves, measure it: Taylor's impact on higher education, in C. Evans and L. Holmes (eds.) Re-Tayloring management: Scientific management a century on, Farnham, Surrey: Gower.

Boswell, W.R. \& Olson-Buchanan, J.B. (2007). The use of communication technologies after hours: The role of work attitudes and work-life conflict. Journal of Management 33(4), 592610.

Bothma, C. \& Cant, M. (2011). Adopting learning technologies: from belief to practice. Educational Studies, 37(4), 375-389.

Brady, M. (2013). Multiple roles of student and instructor in university teaching and learning processes. International Journal of Management Education, 11(2), 93-106.

Bryman, A. \& Bell, E. (2011). Business research methods. Oxford: Oxford University Press (third edition).

Brynjolfsson, E. \& McAfee, A. (2012). Winning the race with ever-smarter machines. MIT Sloan Management Review, 53(2), 53-60.

Buchanan, T., Sainter, P. \& Saunders, G. (2013). Factors affecting faculty use of learning technologies: implications for models of technology adoption. Journal of Computing in Higher Education, 25(1), 1-11. 
Chou, A.Y. \& Chou, D.C. (2011). Course management systems and blended learning: An innovative learning approach. Decision Sciences Journal of Innovative Education 9(4), 463 484.

Coaldrake, P., \& Stedman, L. (1999). Academic work in the twenty-first century, Occasional paper series, no. 99H, Higher Education Division, Department of Education, Training and Youth Affairs, Commonwealth of Australia, (September), 1-35.

Coates, H., James, R. \& Baldwin, G. (2005). A critical examination of the effects of learning management systems on university teaching and learning. Tertiary Education and Management 11(1), 19-36.

Conole, G., de Latt, M., Dillon, T. \& Darby, J. (2008). 'Disruptive technologies', 'pedagogical innovation': What's new? Findings from an in-depth study of students' use and perception of technology. Computer \& Education, 50(2), 511-524.

Cramp, A. (2015). Meaningful dialogue in digitally mediated learning for in-service teacher development. Technology, Pedagogy and Education, 24(1), 1-16.

Creswell, J. W. (2012). Qualitative Inquiry and Research Design: Choosing Among Five Approaches (Third). SAGE Publications.

Dery, K., Kolb, D. \& MacCormick, J. (2014). Working with connective flow: how smartphone use is evolving in practice. European Journal of Information Systems, 23(5), $558-570$.

Garrison, D.R. \& H. Kanuka. (2004). Blended learning: Uncovering its transformative potential in higher education. The Internet and Higher Education, 7(2), 95-105.

Geddes, D. (2009). How am I doing? Exploring on-line gradebook monitoring as a selfregulated learning practice that impacts academic achievement. Academy of Management Learning \& Education, 8(4), 494-510.

Head, K. (2014). The hidden costs of MOOCs, in S.D. Krause and C. Lowe (eds.) Invasion of the MOOCs: The promise and perils of Massive Open Online Courses, Anderson, SC: Parlor Press, pp. 45-55. Available at http://www.parlorpress.com/pdf/invasion_of_the moocs.pdf accessed 16 Oct 2014.

Jackson, S., \& Fearon, C. (2014). Exploring the role and influence of expectations in achieving VLE benefit success. British Journal of Educational Technology, 45(2), 245-259.

Johannesen, M., Erstad, O. \& Habib, L. (2012). Virtual learning environments as sociomaterial agents in the network of teaching practice. Computers \& Education, 59, 785 792.

Kanuka, H. \& Rourke, L. (2008). Exploring amplifications and reductions associated with elearning: conversations with leaders of e-learning programs. Technology, Pedagogy and Education, 17(1), 5-15. 
Kidd, T. (2010). Butterfly under a pin: exploring the voices and stories told of faculty who adopt ICT's for teaching and learning practices. Education and Information Technologies, 15(3), 155-170.

King, A. (1993). From sage on the stage to guide on the side. College Teaching, 41(1), 30-35.

Laverty, S. M. (2003). Hermeneutic Phenomenology and Phenomenology: A Comparison of Historical and Methodological Considerations. International Journal of Qualitative Methods, 2(3), 1-31.

Lonn, S., \& Teasley, S. D. (2009). Saving time or innovating practice: Investigating perceptions and uses of Learning Management Systems. Computers and Education, 53(3), 686-694.

Love, N., \& Fry, N. (2007). Accounting students' perceptions of a virtual learning environment: Springboard or safety net? Accounting Education: An International Journal, 15(2), 151-166.

Mahdizadeh, H., Biemans, H., \& Mulder, M. (2008). Determining factors of the use of elearning environments by university teachers. Computers \& Education, 51, 142-154.

Mason, J. (2002). Qualitative researching (2nd ed.). London: SAGE.

Menzies, H. \& Newson, J. (2007). No time to think: academics' life in the globally wired university. Time \& Society, 16(1), 83-98.

Middleton, C.A. \& Cukier, W. (2006). Is mobile email functional or dysfunctional? Two perspectives on mobile email usage. European Journal of Information Systems, 15, 252-260.

Morgan, G. (2003). Faculty use of course management systems. EDUCAUSE Center for Applied Research, available at http://net.educause.edu/ir/library/pdf/EKF/ekf0302.pdf, accessed 11th November, 2016.

Nagy, J. (2016). Using learning management systems in business and economics studies in Hungarian higher education. Education and Information Technologies, 21, 897-917.

Naveh, G., Tubin, D. \& Pliskin, N. (2010). Student LMS use and satisfaction in academic institutions: The organizational perspective. Internet and Higher Education, 13(3), 127-133.

Nonaka, I. (1991). The knowledge-creating company. Harvard Business Review, 69(6), 96104.

Parker, L.D. (2002). It's been a pleasure doing business with you: a strategic analysis and critique of university change management. Critical Perspectives on Accounting, 13(5/6), 603619.

Parker, M. (2014). University, Ltd: Changing a business school. Organization, 21(2), 281292. 
Prichard, C. \& Thomas, R. (2014). What have we done with higher education? Organization, 21(2), 266-267.

Privateer, P. (1999). Academic technology and the future of higher education: strategic paths taken and not taken. Journal of Higher Education, 70(1), 60-79.

Proserpio, L. \& Gioia, D.A. (2007). Teaching the virtual generation. Academy of Management Learning and Education, 6(1), 69-80.

Schmidt, K. (2002). The web-enhanced classroom. Journal of Industrial Technology, 18(2), $1-6$.

Schoonenboom, J. (2014). Using an adapted, task-level technology acceptance model to explain why instructors in higher education intend to use some learning management system tools more than others. Computers \& Education, 71, 247-256.

Selwyn, N. (2016). Digital downsides: exploring university students' negative engagements with digital technology. Teaching in Higher Education, 21(8), 1006-1021.

Shelton, C. (2017). Giving up technology and social media: why university lecturers stop using technology in teaching. Technology, Pedagogy and Education, 26(3), 303-321.

Strauss, A. \& Corbin, J. (1990). Basics of qualitative research: grounded theory procedures and techniques. Sage.

Tarafdar, M., D’Arcy, J., Turel, O. \& Gupta, A. (2015). The dark side of information technology. MIT Sloan Management Review, 56(2), 61-70.

Walker, R., Voce, J. \& Jenkins, M. (2016). Charting the development of technologyenhanced learning developments across the UK higher education sector: a longitudinal perspective (2001-2012). Interactive Learning Environments, 24(3), 438-455.

Walker, R., Jenkins, M. \& Voce, J. (2018). The rhetoric and reality of technology-enhanced learning developments in UK higher education: reflections on recent UCISA research findings (2012-2016). Interactive Learning Environments, 26(7), 858-868.

West, R. E., Waddoups, G., \& Graham, C. R. (2007). Understanding the experiences of instructors as they adopt a course management system. Educational Technology Research and Development, 55(1), 1-26.

Westberry, N., McNaughton, S., Billot, J. \& Gaeta, H. (2015). Resituation or resistance? Higher education teachers' adaptations to technological change. Technology, Pedagogy and Education, 24(1), 101-116.

van Damme, D. (2001). Quality issues in the internationalisation of higher education. Higher Education, 41(4), 415-441.

Zhu, C. (2015). Organisational culture and technology-enhanced innovation in higher education. Technology, Pedagogy and Education, 24(1), 65-79. 


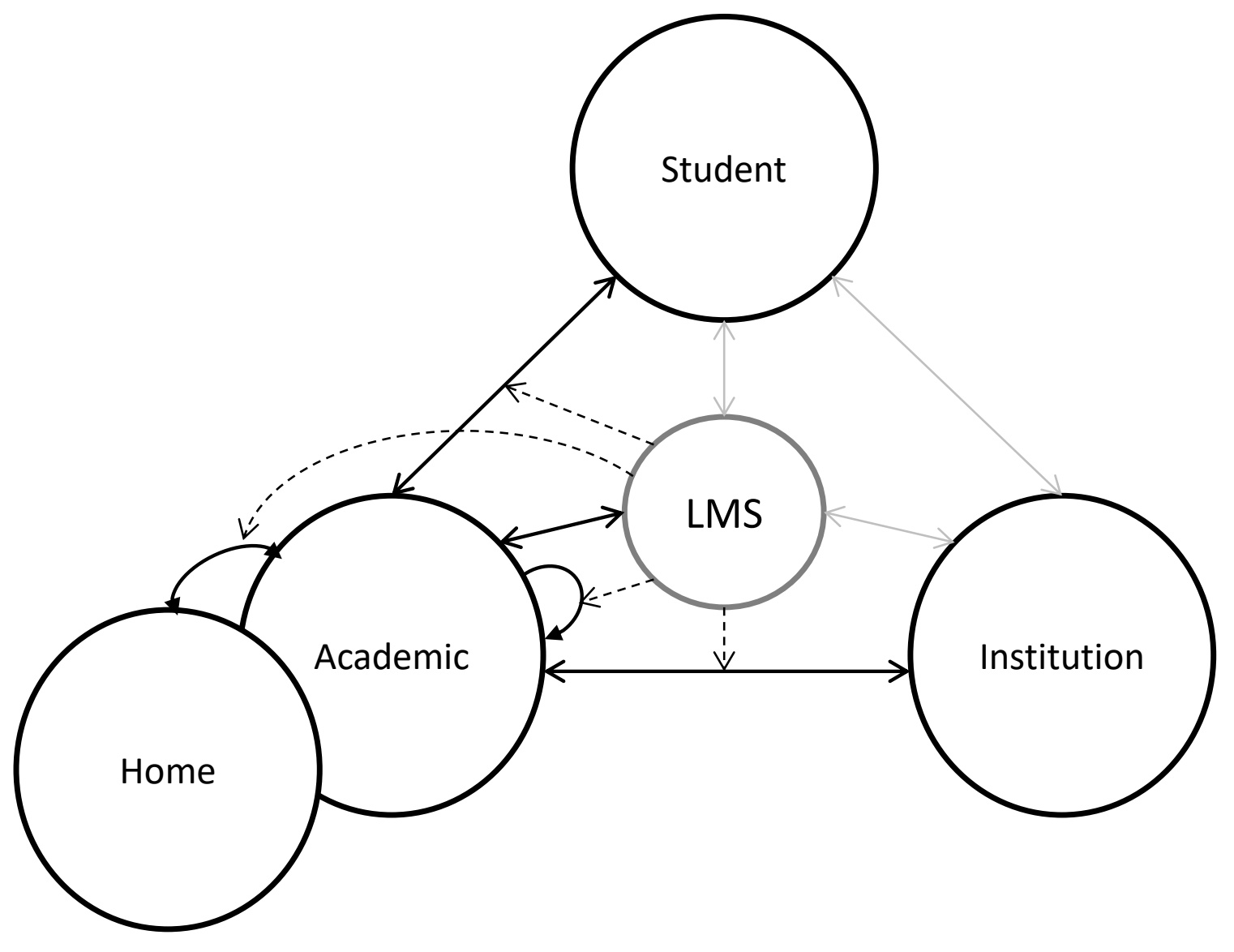

Figure 1: LMS and the academic: a framework for research 
Table 1. Interview questions

1. Can you talk to us a little bit about the way that you use [LMS] currently?

1a. Are there particular features that you use a lot?

1b. Are there features that you think are more valuable?

2. Why do you use [LMS]?

3. If you had to describe [LMS] to somebody who had never seen it, how would you describe it?

4. Do you have particular times when you update your [LMS] pages?

5. Thinking about your interactions with students, how would you say that [LMS] has impacted on these?

5a. Has it changed where and when you respond to students?

$5 b$. Do you think that it is changed how students interact with academics?

5c. Do you think the nature of the material that you make available on [LMS] has implications for your relationship with students?

6. Do you think that [LMS] has changed how you interact with colleagues?

6a. Do you feel under pressure from colleagues to alter how you use [LMS]?

6b. Do colleagues generally have expectations of what might be available on your [LMS] page?

6c. Do colleagues inheriting courses have expectations of what might be available on your [LMS]

page?

7. Do you think that [LMS] generally has implications for how academic staff members are seen by the University?

7a. Are you personally concerned about this?

8. Do you use [LMS] off-campus?

8a. Why do you do this?

9. Thinking about [LMS] overall, would you say it is a positive or a negative thing for the University?

9a. For students?

9b. For academic staff?

10. Is there anything else that we should have asked for that you'd like to say? 
Table 2. Research Categories

\begin{tabular}{|c|c|c|}
\hline Area & Category & Description \\
\hline Usage & Passive or active & $\begin{array}{l}\text { Extent to which instructor uses the LMS in an pro- } \\
\text { active or passive manner }\end{array}$ \\
\hline Usability & Smooth or clunky & Extent to which it is easy to use the LMS \\
\hline \multirow[t]{2}{*}{ Ubiquity } & Always on & $\begin{array}{l}\text { Extent to which the instructor uses the LMS in } \\
\text { terms of time of day/ day of year }\end{array}$ \\
\hline & Available everywhere & $\begin{array}{l}\text { Extent to which the instructor uses the LMS on a } \\
\text { geographic scale }\end{array}$ \\
\hline \multirow[t]{4}{*}{ Purpose } & Repository & $\begin{array}{l}\text { Extent to which the instructor uses the LMS as a } \\
\text { repository }\end{array}$ \\
\hline & Assessment & $\begin{array}{l}\text { Extent to which the instructor uses the LMS for } \\
\text { assessment purposes }\end{array}$ \\
\hline & Communication & $\begin{array}{l}\text { Extent to which the instructor uses the LMS to } \\
\text { communicate with students }\end{array}$ \\
\hline & Administration & $\begin{array}{l}\text { Extent to which the instructor uses the LMS for } \\
\text { course management and administration }\end{array}$ \\
\hline \multirow[t]{3}{*}{ Motive } & Efficiency & To improve the efficiency of the person's teaching \\
\hline & Engagement & To increase student engagement with materials \\
\hline & Monitoring and Control & To monitor and control student learning activity \\
\hline \multirow[t]{4}{*}{ Relationship } & With students & $\begin{array}{l}\text { The extent to which use of LMS alters the } \\
\text { relationship between the academic and the } \\
\text { student }\end{array}$ \\
\hline & With colleagues & $\begin{array}{l}\text { The extent to which use of LMS alters the } \\
\text { relationship between the academic and } \\
\text { colleagues }\end{array}$ \\
\hline & With the institution & $\begin{array}{l}\text { The extent to which use of LMS alters the } \\
\text { relationship between the academic and the } \\
\text { institution }\end{array}$ \\
\hline & With home & $\begin{array}{l}\text { The extent to which use of LMS alters the } \\
\text { relationship between the academic and home }\end{array}$ \\
\hline $\begin{array}{l}\text { Protective } \\
\text { action }\end{array}$ & Protective action & $\begin{array}{l}\text { Extent to which instructors took action to protect } \\
\text { their materials }\end{array}$ \\
\hline
\end{tabular}

